\title{
The Effect of Group Counseling Based on Cognitive Behavioral Therapy on Anxiety of Pregnant Women with Constipation: Clinical Trial
}

\author{
Solmaz Ghorbani ${ }^{1}$, Zinat Jourabchi ${ }^{2}$, Mohammad ebrahim Sarichloo ${ }^{3}$, Forouzan Olfati ${ }^{4 *}$
}

1. MSc. Master Student, Department of Midwifery Counseling, Student Research Committee of Qazvin University of Medical Sciences, Qazvin, Iran

2. Assistant Professor, Social Determinants of Health Research and Department of Midwifery, School of Nursing and Midwifery, Qazvin University of Medical Sciences, Qazvin, Iran

3. PhD Student, Department of Psychiatry, Faculty of Medicine, Qazvin University of Medical Sciences, Qazvin, Iran

4. Assistant Professor, Metabolic Diseases Research Center and Department of Midwifery, School of Nursing and Midwifery, Qazvin University of Medical Sciences, Qazvin, Iran

\section{Article Info}

Received: 2020/01/07;

Accepted: 2020/04/26;

Published Online: 2020/10/21

10.30699/ajnmc.28.4.32

Original Article

Use your device to scan and read the article online

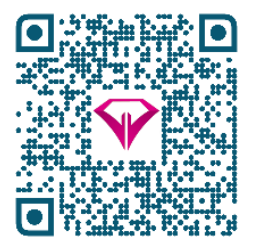

\section{ABSTRACT}

Introduction: Anxiety during pregnancy is a special emotional state related with different concerns during pregnancy including infant health and parturition, which is associated with an increased risk of a range of negative consequences for both mother and child. Therefore, the aim of this study was to investigate the effect of cognitive and behavioral therapy on the anxiety of mothers with pregnancy constipation.

Methods: The present randomized clinical trial, which included 60 pregnant women with gestational age of 10 to 20 weeks referred to two comprehensive urban health services in Takestan during 2019. Subjects were randomly divided into intervention $(n=30)$ and control $(n=30)$ groups. Study tools included the short form of pregnancy-related anxiety questionnaire (PRAQ-17) and a constipation assessment scale in pregnancy. Intervention included 6-week 90-minute consultation sessions (one session each week) for five groups of 6 persons. Follow-up included immediately and one and two months after session completion. Repeated measures and Chi-square analysis were used for data analysis. P-value $<0.05$ was considered significant.

Results: The mean of pregnancy anxiety scale, immediately, one month and two months after the intervention was significant $(P<0.001)$. In terms of time and group interaction significant difference was observed $(P<0.001 ; \mathrm{F}=29.776)$, In other words, there was a significant difference between the two groups in terms of pregnancy anxiety over time.

Conclusion: The present study indicated the beneficial effect of cognitive and behavioral therapy model on the anxiety of pregnant women with constipation, and it is recommended as a non-pharmacological approach to reduce their anxiety.

Keywords: Counseling, Cognitive behavioral therapy, Anxiety, Constipation, Pregnant woman, pregnancy.

Copyright $($ C 2020, This is an original open-access article distributed under the terms of the Creative Commons Attribution-noncommercial 4.0 International License which permits copy and redistribution of the material just in noncommercial usages with proper citation.

How to Cite This Article:

Ghorbani S, Jourabchi Z, Sarichloo O E, Olfati F. The Effect of Group Counseling Based on Cognitive Behavioral Therapy on Anxiety of Pregnant Women with Constipation: Clinical Trial. Avicenna J Nurs Midwifery Care. 2020; 28 (4) :32-44 
بررسى تأثير مشاوره كروهى مبتنى بر درمان شناختىرفتارى بر اضطراب زنان باردار مبتلا

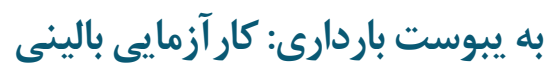

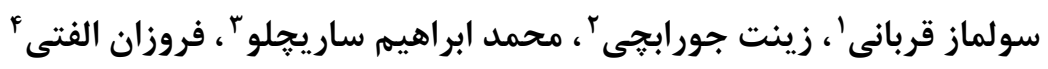

ا. . ارشناسىارشد مشاوره در مامايى، كميته تحقيقات دانشجويى، دانشكده يرستارى و مامايى، دانشكاه علوميزشكى قزوين، قزوين،

r. استاديار، مركز تحقيقات عوامل اجتماعى مؤثر بر سلامت، كروه مامايى، دانشكده يرستارى مامايى، دانشكاه علوميزشكى قزوين،

قزوين، ايران

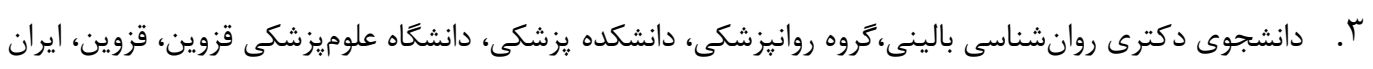

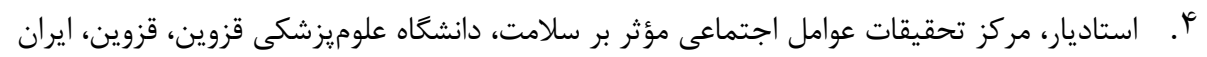

\begin{tabular}{|c|c|}
\hline جكيده & اطلاعات مقاله \\
\hline 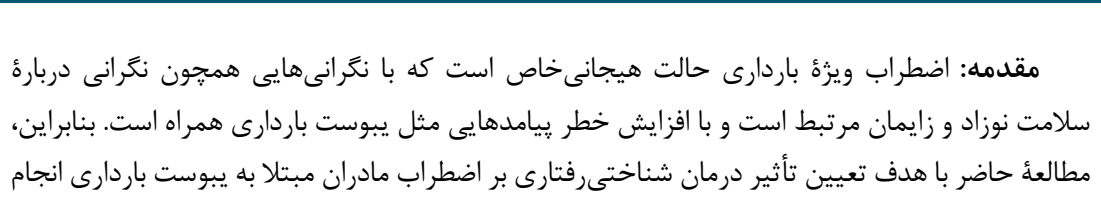 & 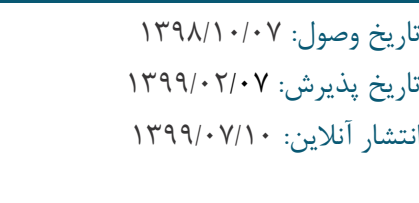 \\
\hline 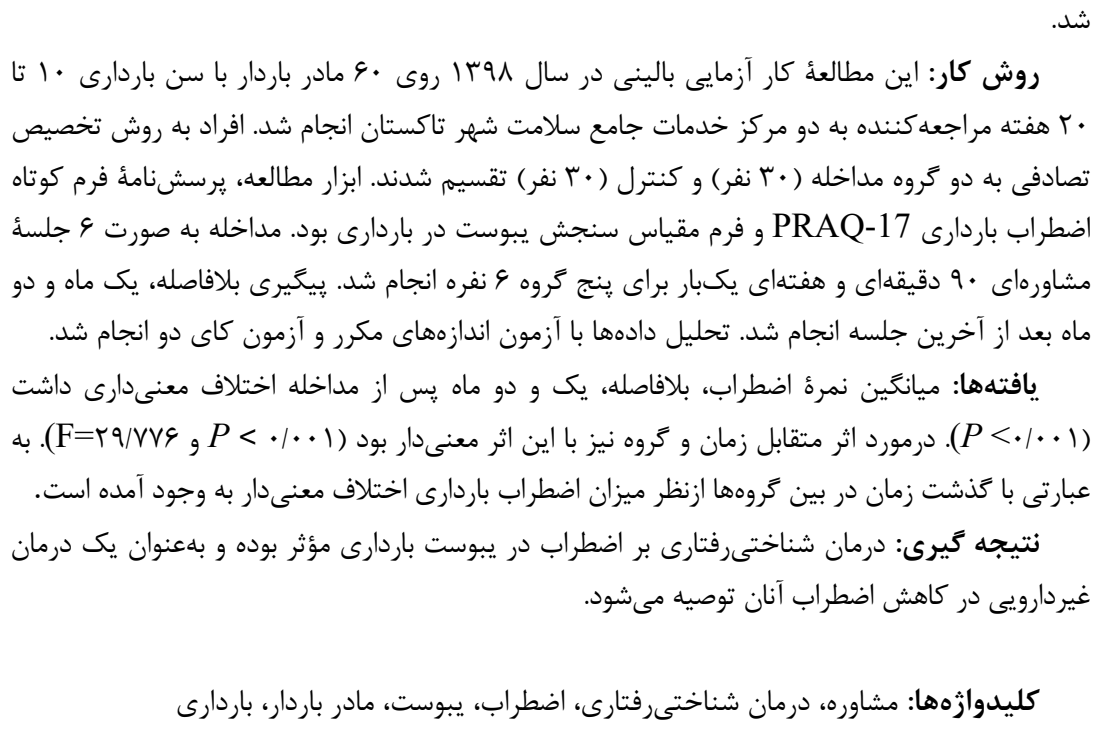 & 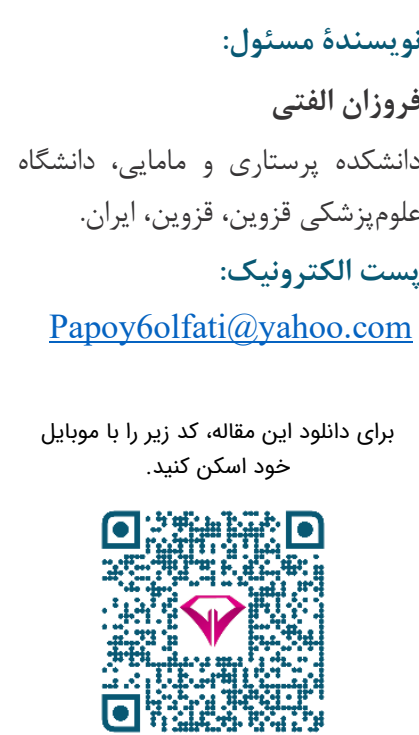 \\
\hline
\end{tabular}

مقدمه

اين نكرانىها مىتواند با سطح بالاى اضطراب دوره باردارى

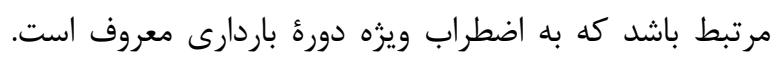

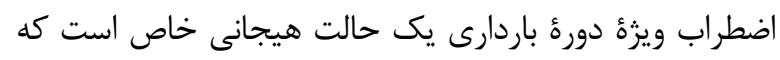

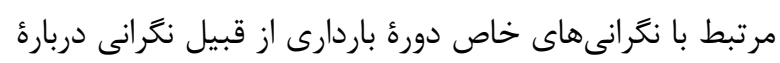

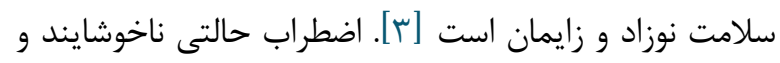

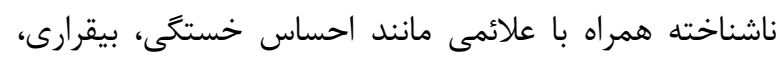

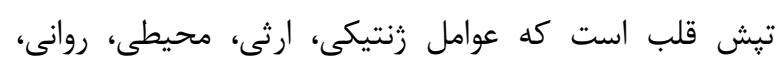

بسيارى از تغييرات باردارى بلافاصله يس از لقاح آغاز

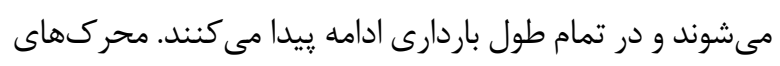

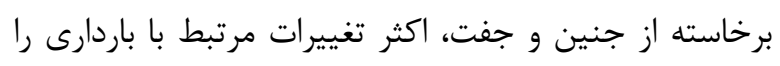

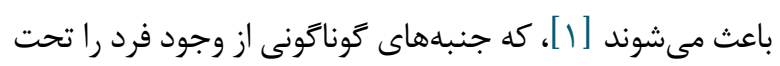

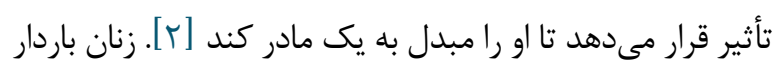

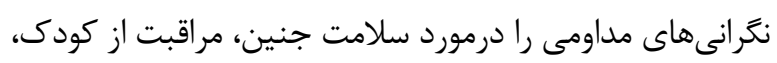

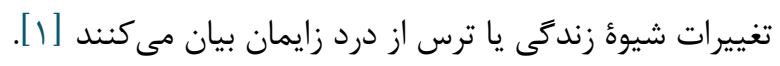


به اجابت مزاج طولانى، دشوار، به دفعات كم يا دفع مدفوع ظاهراً ناكامل اطلاق مىشود. علائم يبوست عبارتند از دفعات اجابت مزاج كمتر از ب بار در هفته ، قوام مدفوع كلولهاى و و سفت،

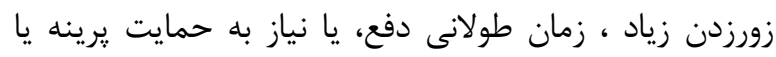

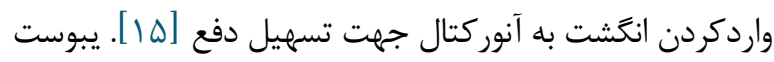

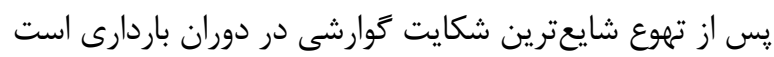

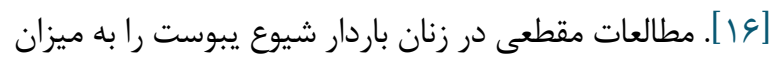

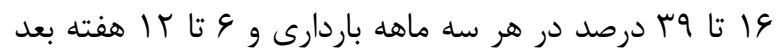
زايمان تعيين كردند. اين ميزان بالاتر از شيوع يبوست در زنان

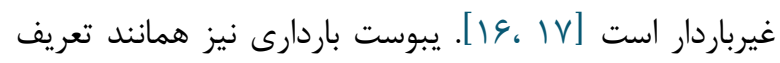

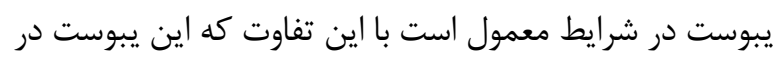

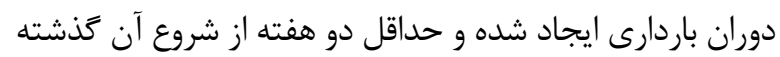

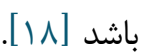

از عوارض يبوست و دفع سخت، تخريب عصب يودندال و و

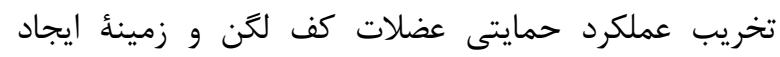

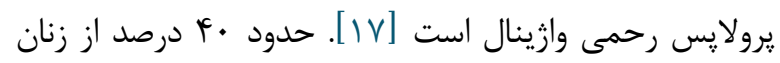

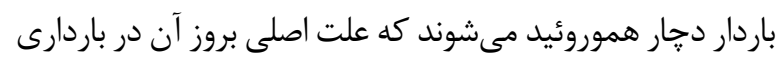

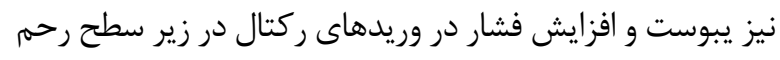

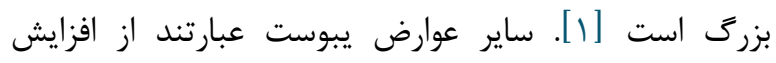

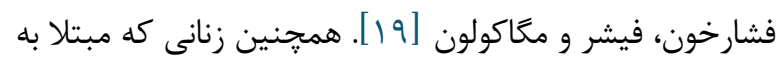

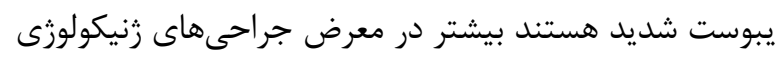

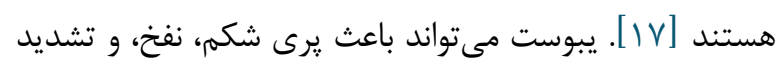

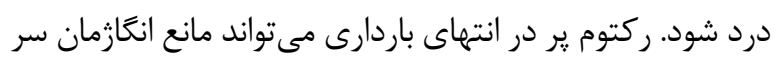
جنين شود [r.r]

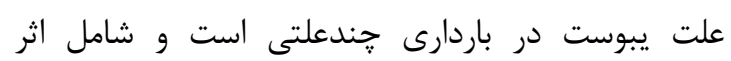
هورمونى،كاهش فعاليت زنان باردار و افزايش مصرف مكمل هاردا

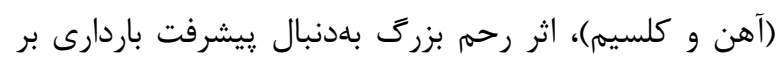

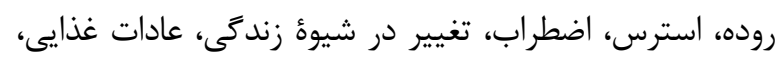

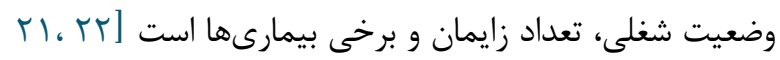

[19.1\%。

مشكلات رفتارى و روانشناختى همراه با يبوست طيف

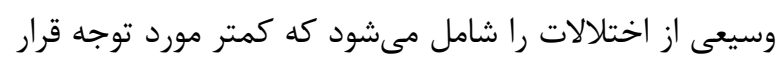

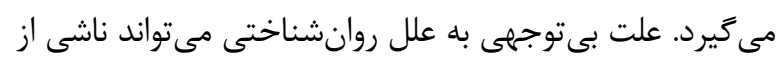

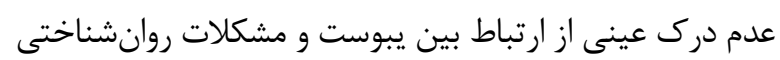

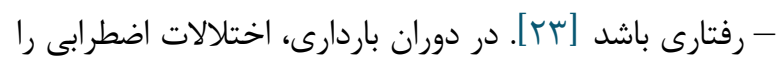

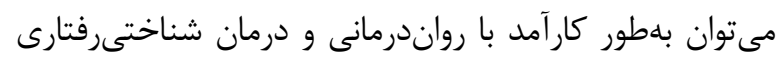

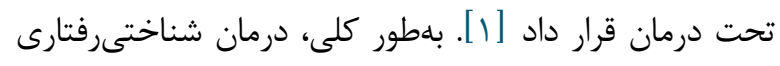

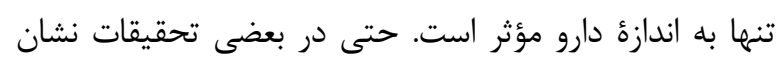

اجتماعى و بيولوزيكى در ايجاد آن مطرح هستند. همجنين

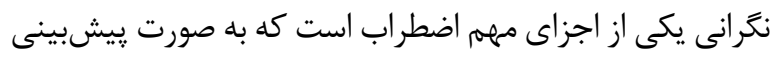

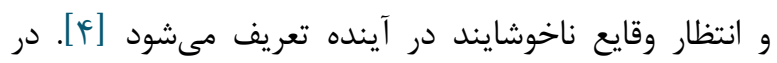
سهماههى اول و سوم ميزان اضطراب و نكرانى افزايش مى ميابد

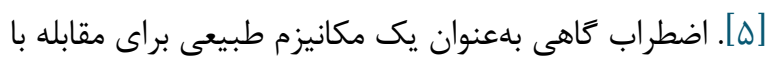

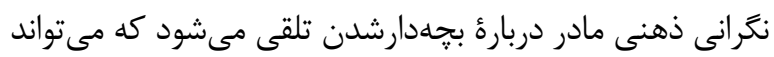

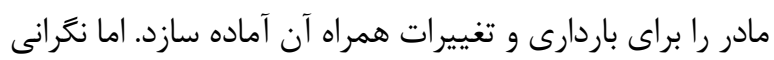

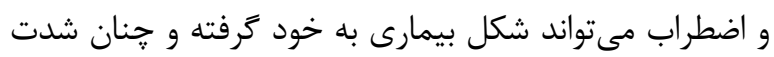

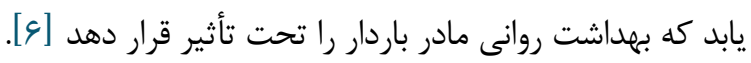

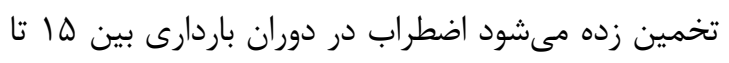

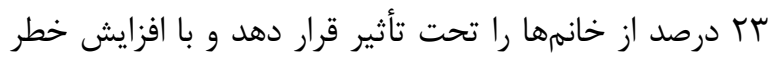
طيف وسيعى از پيامدهاى منفى مادر و كودى در ارتباط است

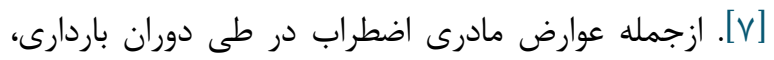

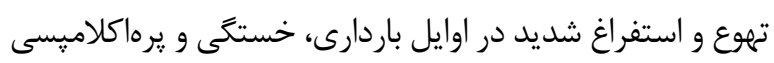

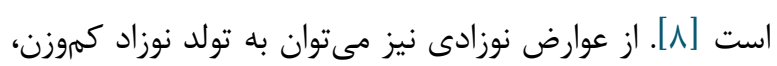

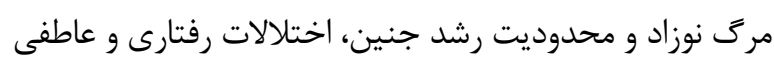

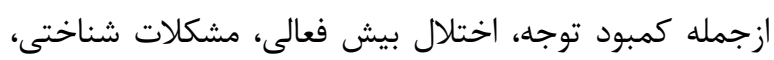

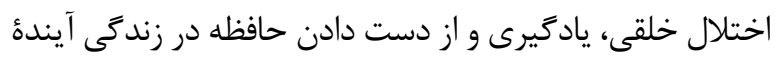
نوزاد اشاره كرد [ [ ، 1]. اختلالات روانشناختى ازجمله اضطراب با تأثير بر محور

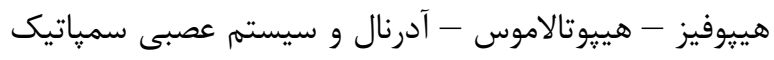

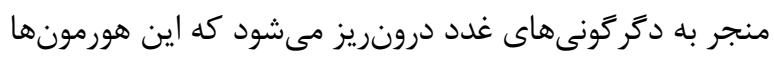

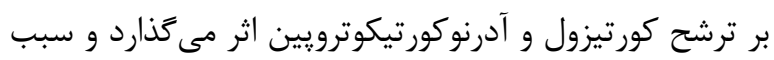

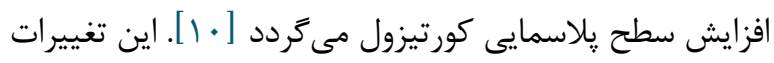

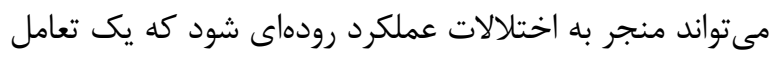

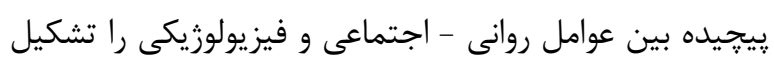

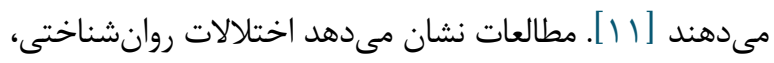

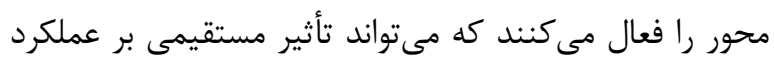

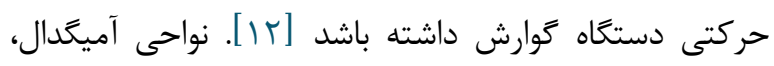

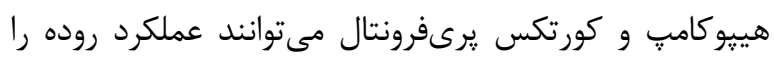

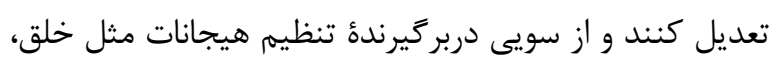
اضطراب، عواطف منفى و درد و رفتارهاى شناختى مثل حل حل دئل

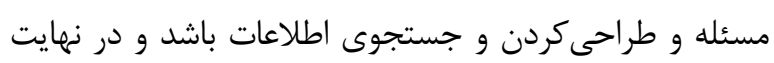

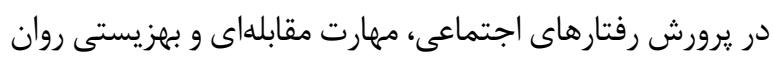

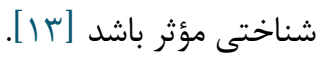
اختلالات رودهاى عملكردى شامل طيف وسيعى از علائم

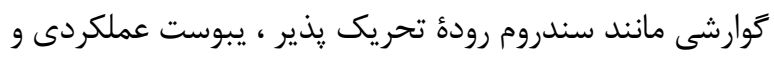
درد شكمى است [4 [ ] ]. يبوست يكى شكايت شايع است و معمولاًا 
ابتلا به سندروم رودهُ تحريكيذير و يبوست قبل از باردارى (خوداظهارى)، سابقُ بيمارىهاى گَوارشى، سابقهُ جراحى روده، بروز عوارض باردارى در باردارى فعلى (باردارى يرخطر كه نياز بهابه

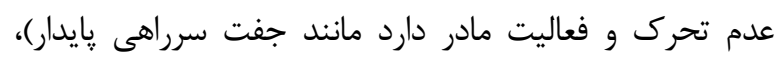
داشتن سابقهُ نازايى ييش از اين باردارى، مصرف داروهاى مؤثر بر

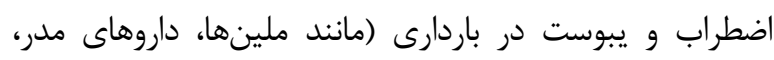
ضددردهاى مخدر ، ضدافسردگى) بود.

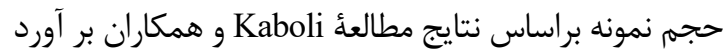

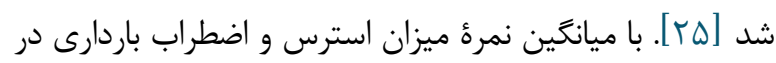

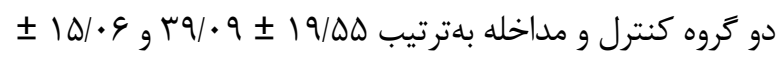

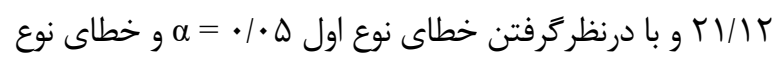

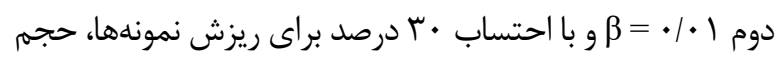

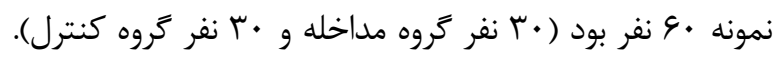

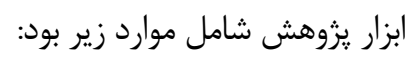

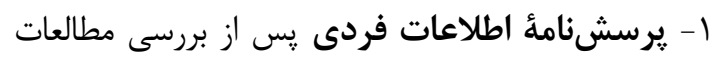

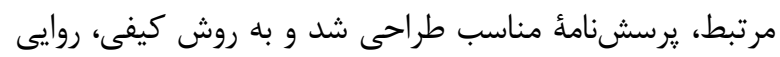

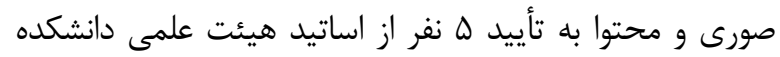

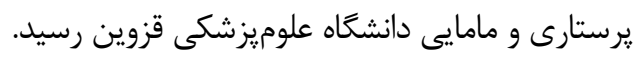

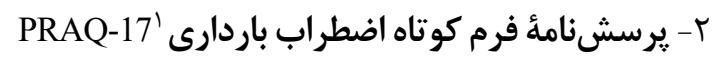

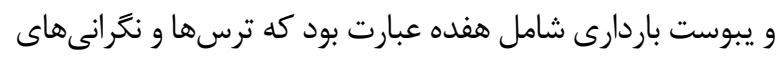

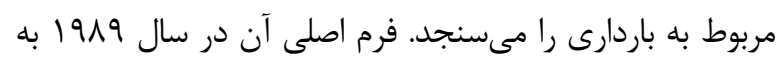

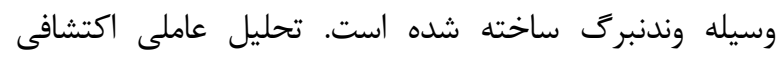

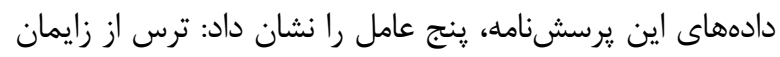

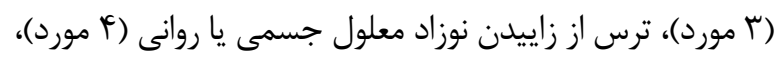

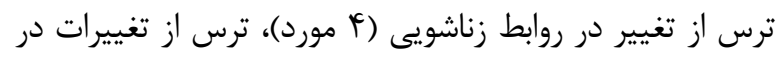

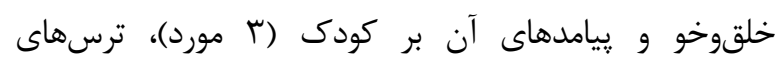

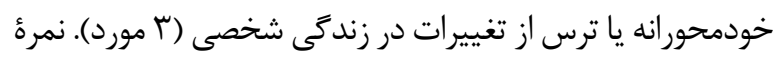

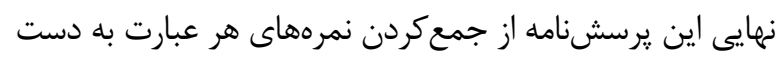

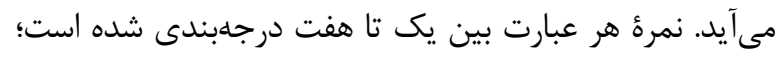

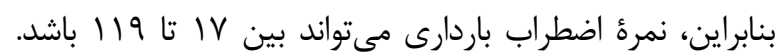

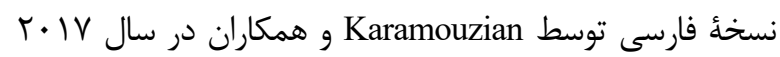

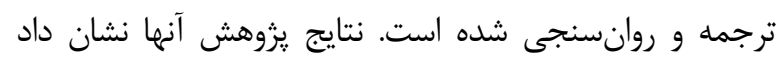

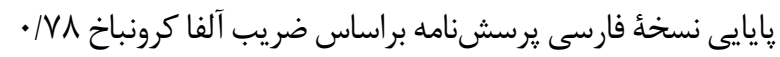

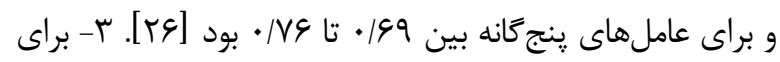

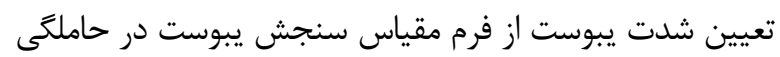

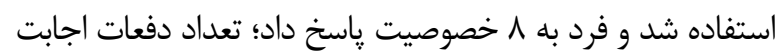

داده شده كه درمان شناختىرفتارى مؤثرتر از دارو است [F][].

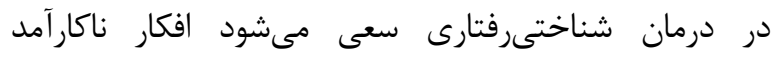

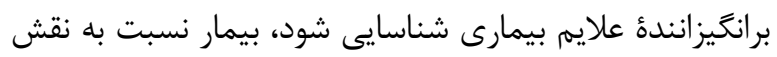

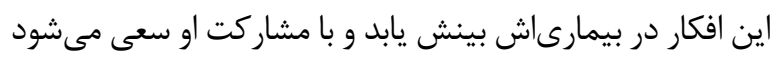

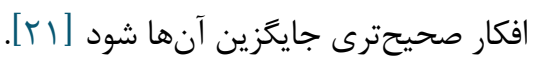

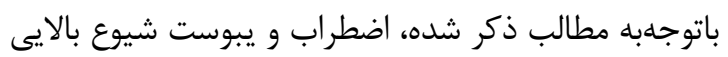

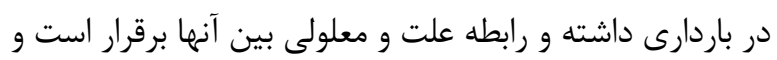

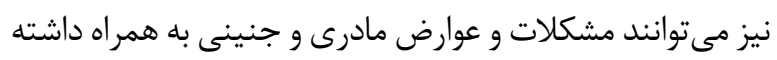

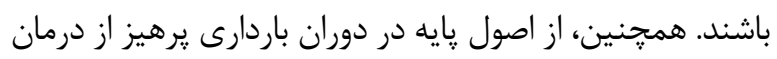

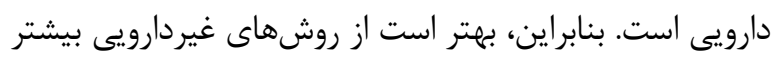

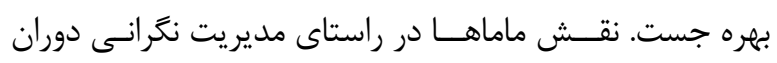

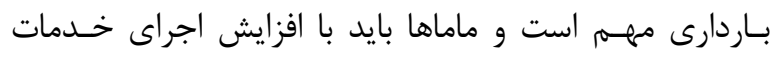

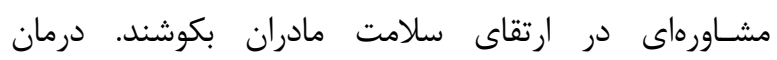

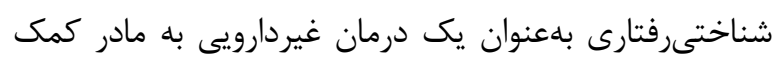

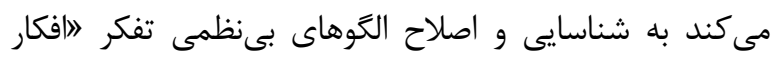

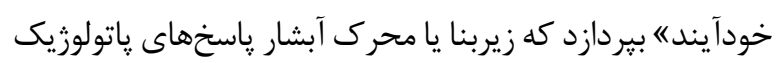

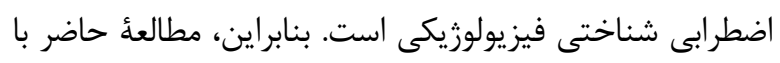

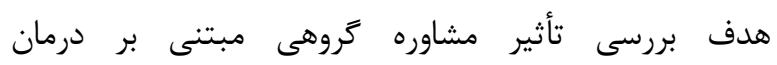
شناختىرفتارى بر اضطراب و يبوست زنان باردار طراحى شد.

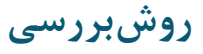

مطالعُ حاضر يك مطالعة كارآزمايى بالينى شاهددار تصادفى

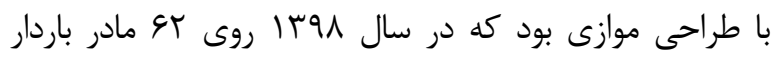

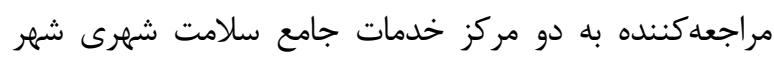

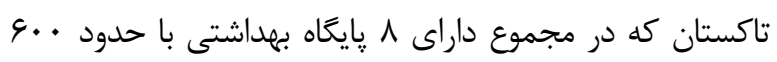

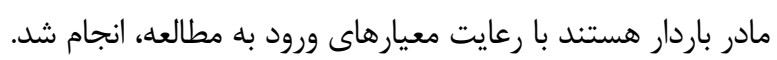

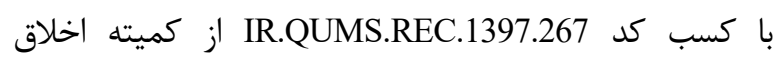

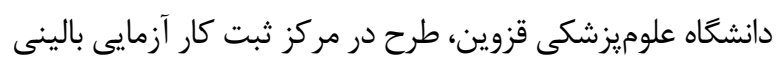
ايران با كد IRCT20181205041852N1 ثبت و تأييد شد. معيارهاى ورود به مطالعه شامل تكققلويى، سن باردارى بين

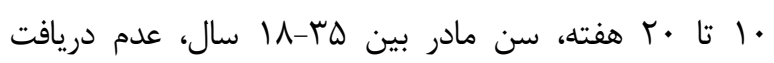

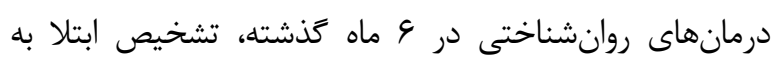

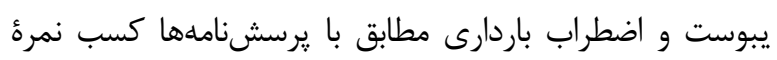

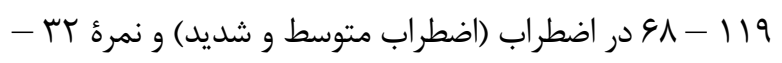

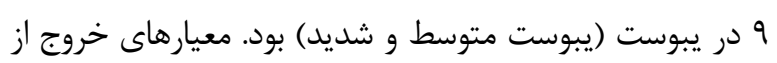
مطالعه نيز شامل ابتلا به بيمارىهاى روانى (خوداظهارى)، سابقه

\footnotetext{
${ }^{1}$ Pregnancy Related Anxiety Questionnaire (PRAQ)
} 
براى دو گروه اسامى B, A در نظر كرفته شد، به اين صورت كه

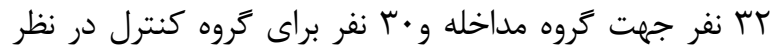
كرفته شد. حروف به تعداد شركت كنندكان روى تكههاى كاغذ

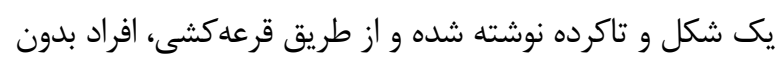
جايكزينى كاغذها را انتخاب كردند، سيس توالى ايجادشده ثبت شد. بدين طريق زنان مبتلا به دو كروه مداخله كب نفرى (كروهى

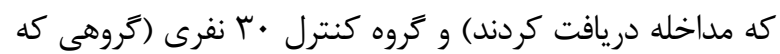
مداخله دريافت نكردند) تقسيم شدند. مطالعه به صورت يكى سو كور طراحى شد. بدين ترتيب كه افراد نمونه نمى دانستند كه به به

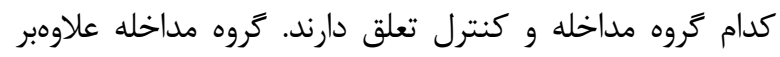

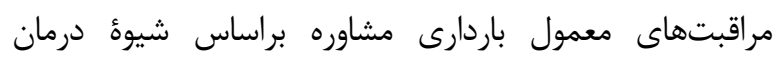
شناختىرفتارى را دريافت كرد و كروه كنترل فقط مراقبتهاى معمول باردارى را دريافت كرد.

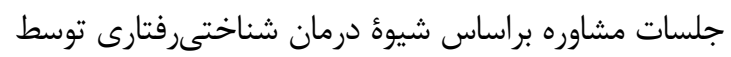

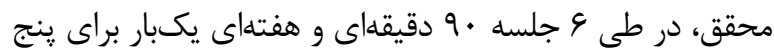
كروه 9 نفره از گروه مداخله در مراكز جامع سلامت بركزار گرديد.

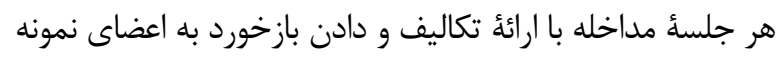
و اجراى تمرينات مناسب و همجنين با مرورى بر جلسأ قبل

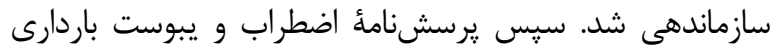

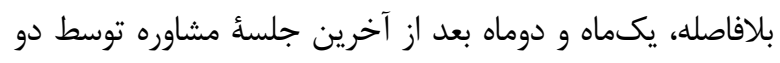

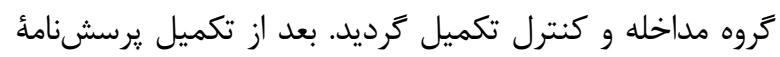

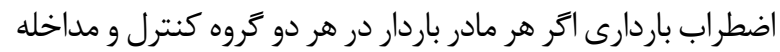

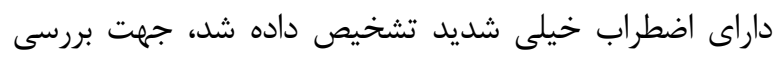

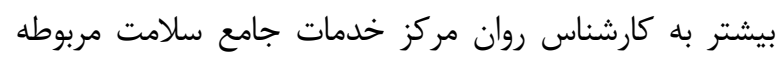

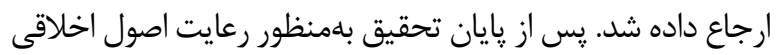
در يزوهش براى تروه كنترل نيز مشابه كروه مورد جلسات مشاوره

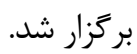

راى تحليل دادهها از نرمافزار SPSS نسخه بr ( SPSS استفاده شد. از روشهاى آمار (inc., Chicago, Ill., USA توصيفى براى ارائٔ اطلاعات كلى، براى مقايسُٔ دو كروه آزمون

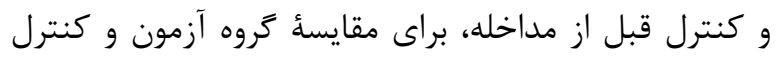
بعد از مداخله از آزمون اندازههاى مكرر (Repeated measure) و براى مقايسُٔ متغيرهاى كيفى از آزمون كاى دو استفاده شد. سطح معنى دارى كمتر از هـ • • • تعيين كرديد.
مزاج، سختى و سفتى مدفوع، درد مقعد هنغام اجابت مزاج، مدت

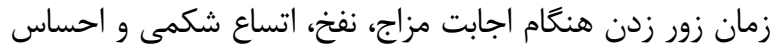

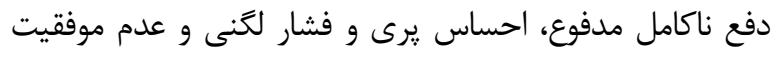

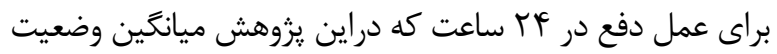
دو هفته قبل زنان باردار مد نظر قرار كرفت. نمرهٔ موردنظر بر دراعر

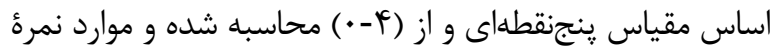

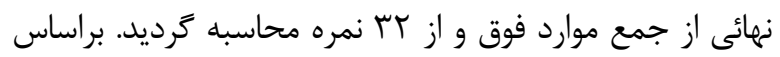
نمره كل كسب شده شدت يبوست به جهار قسمت تقسيم شده،

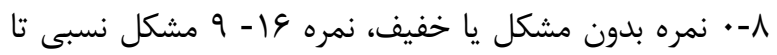

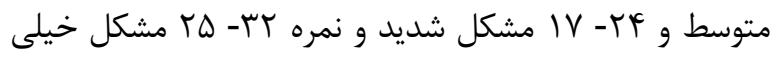

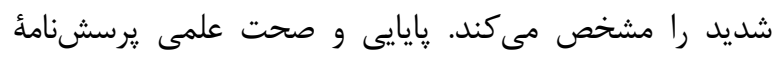

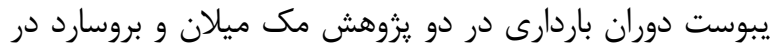

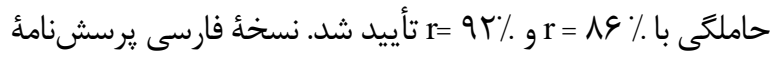
يبوست دوران باردارى نيز در مطالعئ Ghaffari به اثبات رسيده

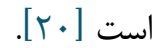

انتخاب واحدهاى مورد يزوهش در دو مرحله صورت گرفت.

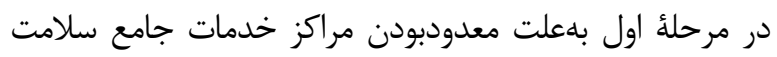

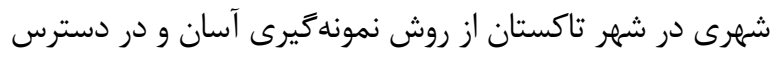
استفاده شد. هر دو مركز خدمات جامع سلامت شهرى شامل 1 ردان

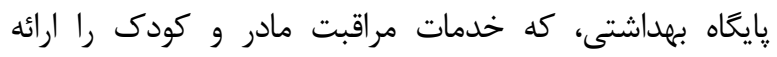
مىدهند، وارد مطالعه شدند. مرحلة دوم هدفمند و مبتنىبر معيارهاى ورود به مطالعه بود. جهت شناسايى افراد و انتخاب اولئ.

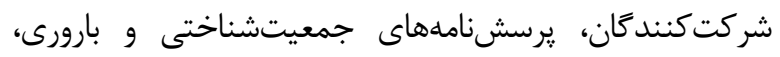

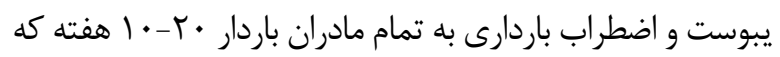

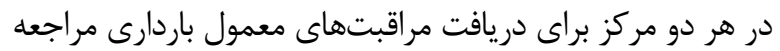

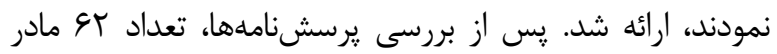

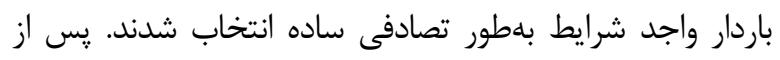

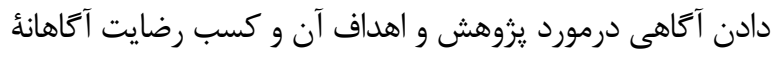
كتبى، در صورت تمايل افراد مورد يزوهش وارد مطالعه شدند.

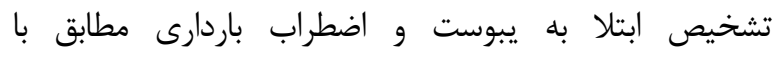
يرسشنامههاى مذكور، كسب نمرة 119 - 119 - 91 در اضطراب (اضطراب متوسط و شديد) و نمرة r ب - 9 در يبوست (يبوست متوسط و شديد) بود. بدين ترتيب ك \& نفر انتخاب شدندكه به

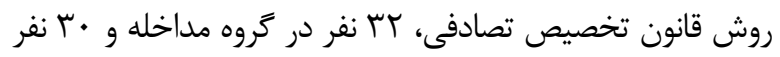
در كروه كنترل قرار كرفتند. بدين صورت كه از قبل در هر مركز، 


\begin{tabular}{|c|c|c|}
\hline 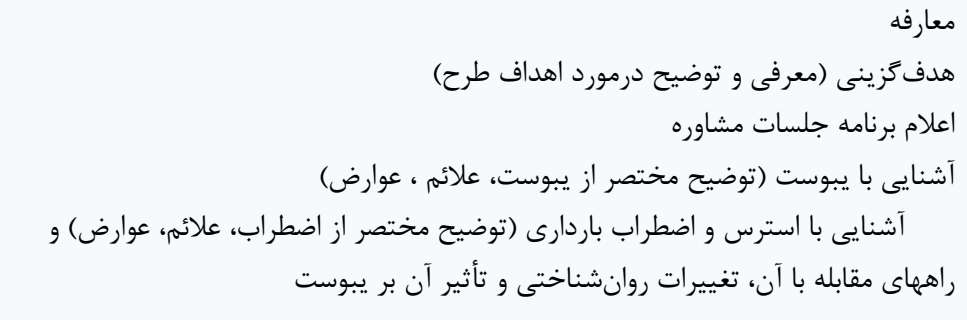 & 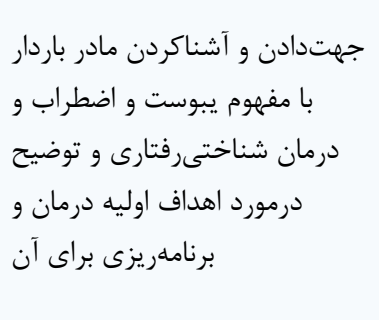 & اول اول \\
\hline 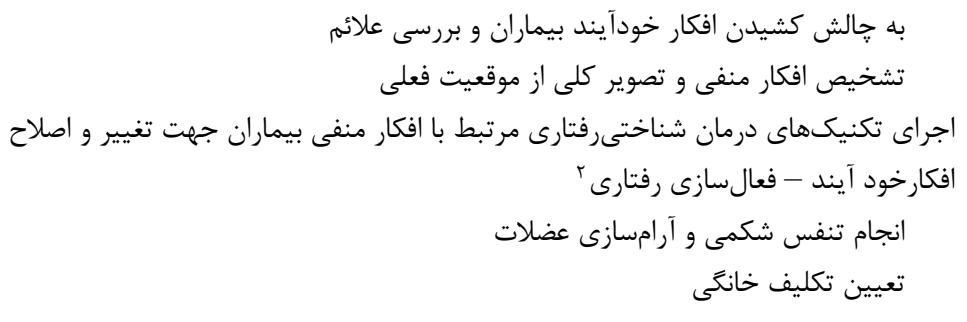 & 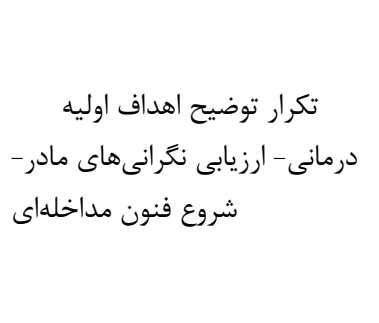 & 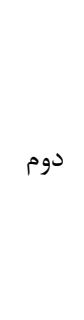 \\
\hline 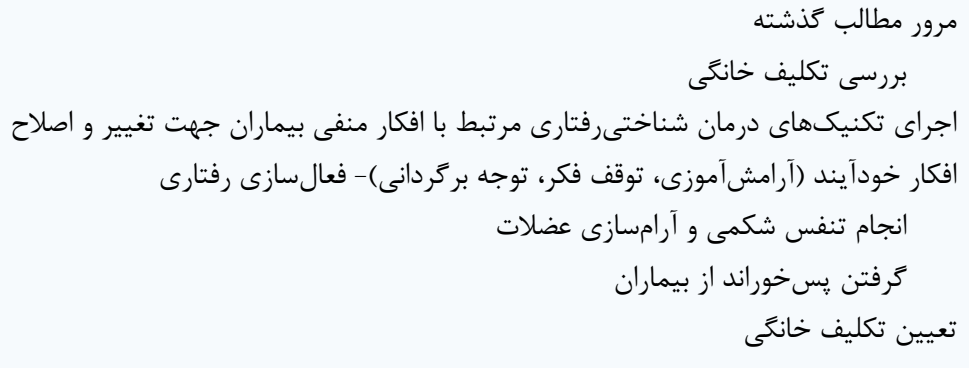 & ادامئ فنون مداخلهاى & سوم \\
\hline 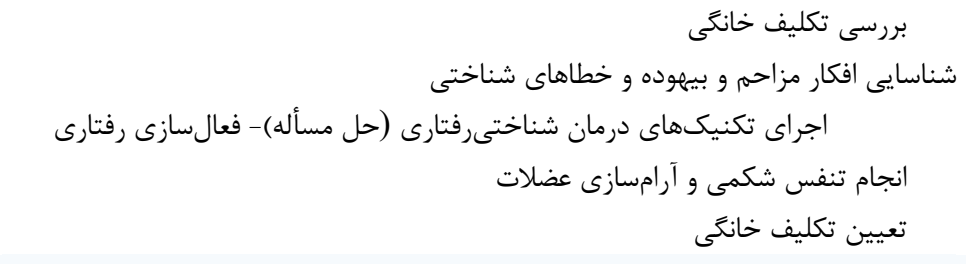 & 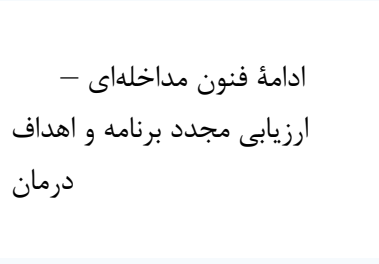 & جهارم - لج \\
\hline 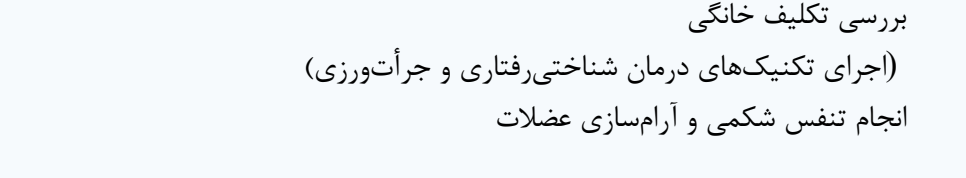 & 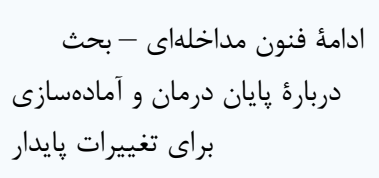 & ينجم \\
\hline تاقدام درخصوص پيشگيرى از عود & يايان برنامه و كمك به مادر & ششم \\
\hline
\end{tabular}

` اين تكنيكها شامل فعالسازى رفتارى (افزايش انرزى، حل مسأله، جرأتورزى)، كاهش اضطراب و شكستن الكَوهاى اجتنابى، آموزش مهارتهاى اساسى متناسب با

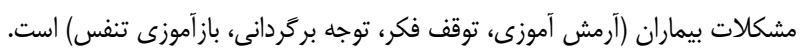




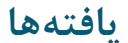

در ارتباط با بررسى و مقايسه اضطراب باردارى، ابتدا مقادير

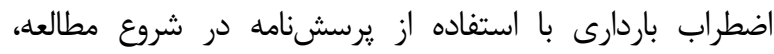

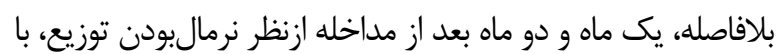
استفاده از آزمون كلموكروف - اسميرنوف مورد بررسى قرار ترفت

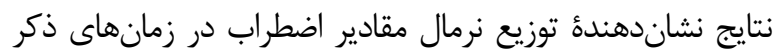

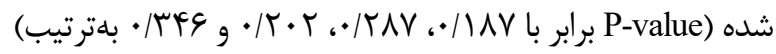
بود. همجنين پِيشفرض كرويت واريانس- كوواريانس نيز كنترل

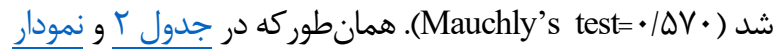

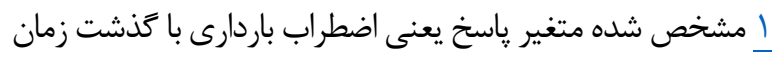

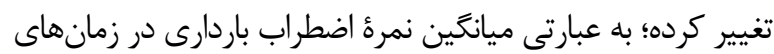
مختلف اختلاف معنى دارى دارد. البته اين موضوع هم درمورد كروه

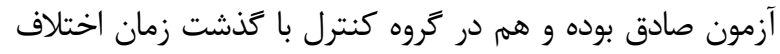

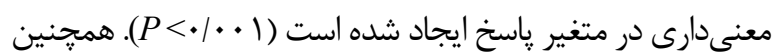

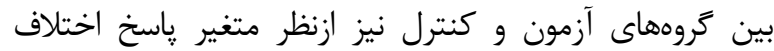

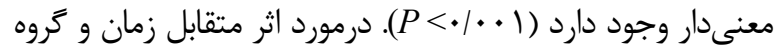

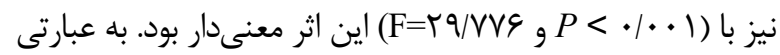
با كذشت زمان در بين كروهها ازنظر ميزان اضطراب باردارى اختلاف

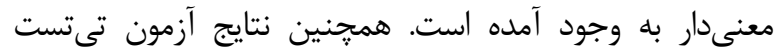

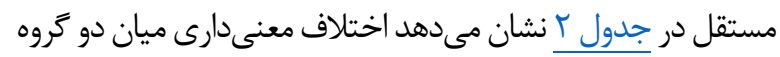
در زمان شروع مطالعه، بلافاصله، يك ماه و دو ماه بعد از مداخله

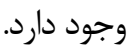

در مطالعهُ حاضر طبق جدول كانسورت تعداد ك و مادر باردار با توجه به معيارهاى ورود و خروج، وارد مطالعه شدند

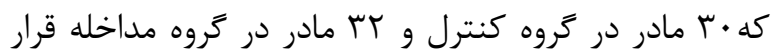
داشتند. تعداد ريزش نمونهها درگروه مداخله r نفر (ا مورد تهديد به زايمان زودرس، ا مورد به علت عدم شركت در

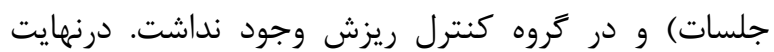

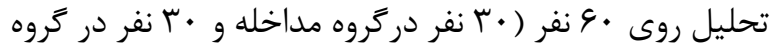

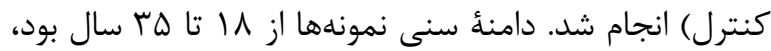

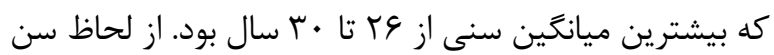
كروه آزمون و كنترل با ميانگين و انحرافمعيار بلهترتيب آنسين 年

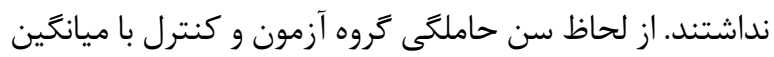

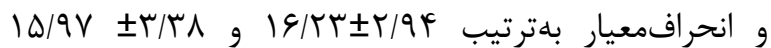
اختلاف آمارى معنىدارى نداشتند. اطلاعات توصيفى مطالعه در جدول إرائه شده است. آزمون كاى اسكوئر نشان داد توزيع فراوانى افراد شركت كننده آردات از جهت سن مادر، مدت ازدواج، تحصيلات مادر، درآمد، مسكن، بيمه، رضايت زناشويى، سابقه سقط، نوع زايمان قبلى، خواستهبودن

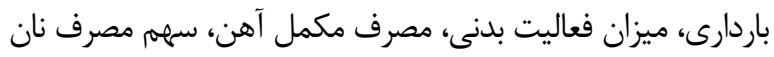
و غلات، سهم مصرف سبزى ميوه و خواب شبانهروز بين دو كروه تفاوت معنادار نداشت (ه •/• (P).

جدول 1. مشخصات جمعيتشناختى دو گروه مداخله و كنترل

\begin{tabular}{|c|c|c|c|c|c|c|c|}
\hline \multirow{2}{*}{$P$} & \multirow{2}{*}{$x^{2}$} & \multicolumn{2}{|c|}{ كنترل } & \multicolumn{2}{|c|}{ مداخله } & & \multirow{6}{*}{ سن مادر } \\
\hline & & درصد & فراوانى & درصد & فراوانى & & \\
\hline \multirow{4}{*}{$\cdot / \mathrm{VA}$. } & \multirow{4}{*}{ T/NT } & $1 . \%$ & 9 & $11 / \mathrm{V}$ & v & $1 \varepsilon-r$. & \\
\hline & & س/سו & $\wedge$ & 1.1 & 4 & $r \mid-r \Delta$ & \\
\hline & & $11 / V$ & V & $\mid \varepsilon / V$ & 1. & rg-r. & \\
\hline & & $\mid \omega /$. & 9 & $11 / v$ & $v$ & هు & \\
\hline \multirow{4}{*}{$\cdot|\Lambda| \Lambda$} & \multirow{4}{*}{.19 .9} & $r e / V$ & 19 & ro/. & 10 & $\cdot-\Delta$ & \multirow{5}{*}{$\begin{array}{c}\text { مدت ازدواج) } \\
\text { (سال) }\end{array}$} \\
\hline & & r/r & $\wedge$ & $\mid N / r$ & 11 & $9-1$. & \\
\hline & & $\Delta / \cdot$ & $r$ & $r / \mu$ & $r$ & $11-10$ & \\
\hline & & $\Delta / \cdot$ & $r$ & س/r & r & $19-r$. & \\
\hline.$/ 1 M 9$ & $1 / T V R$ & $1 / V$ & 1 &.$/$ & . & بىسواد & \\
\hline
\end{tabular}




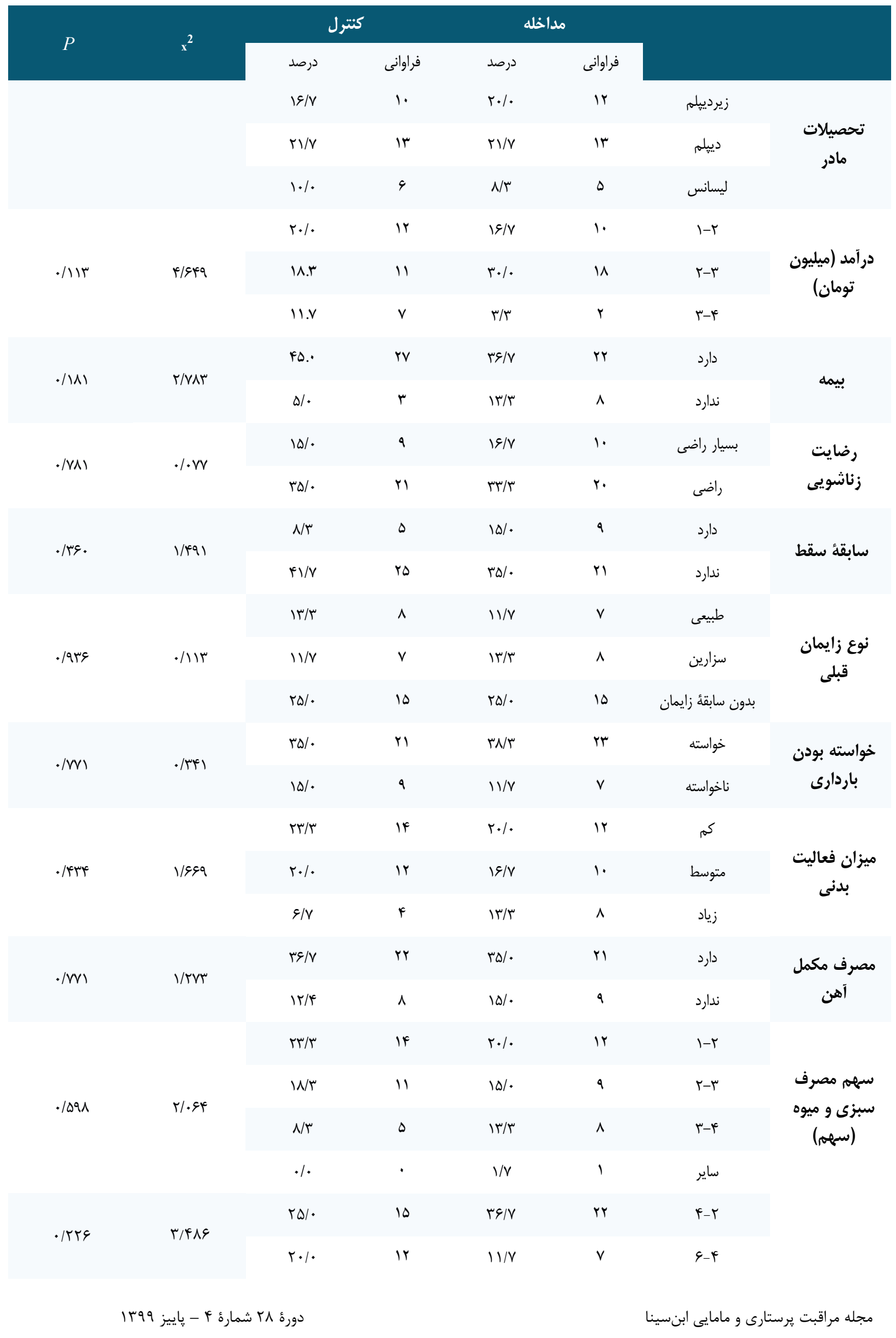




\begin{tabular}{|c|c|c|c|c|c|c|c|}
\hline \multirow{2}{*}{$P$} & \multirow{2}{*}{$x^{2}$} & \multicolumn{2}{|c|}{ كنتر ل } & \multicolumn{2}{|c|}{ مداخله } & & \\
\hline & & درصد & فراوانى & درصد & فراوانى & & \\
\hline & & $\omega / \cdot$ & $r$ & $1 / \mathrm{V}$ & 1 & $1-9$ & سهمم مصرف غلات \\
\hline & & $1 / V$ & 1 & $1 / V$ & 1 & كمتر از ع & \\
\hline & & $1 . \%$ & 9 & $\Delta / \cdot$ & r & $f-9$ & خاد \\
\hline .1190 & $\Delta /$ Q/A & $11 / v$ & v & $r / r$ & r & $1-9$ & شبانهروز \\
\hline & & r & if & r & $\wedge$ & $\Lambda-1$. & (ساعت) \\
\hline & & $r / \mu$ & r & $\Lambda / \Gamma$ & $\Delta$ & بيشتر از • & \\
\hline
\end{tabular}

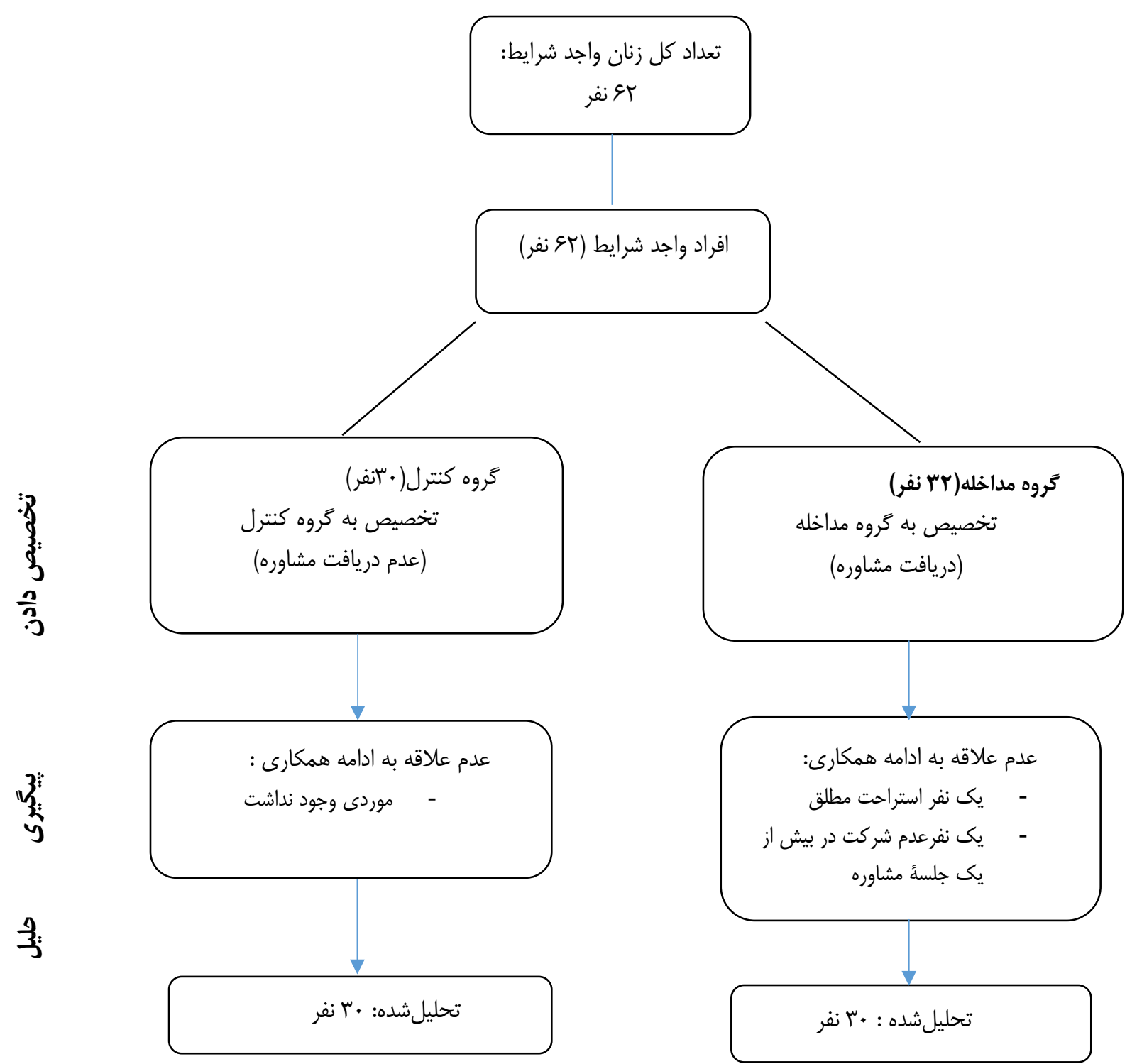

نمودار ا. نمودار كانسورت روند انتخاب و انجام مداخله زنان باردار مبتلا به اضطراب و يبوست 
سولماز قربانى و همكاران

جدول r. مقايسه ميانكَين و انحرافمعيار ميزان اضطراب باردارى در عروههاى آزمون و كنترل قبل و بلافاصله، او r ماه بعد از مداخله

\begin{tabular}{|c|c|c|c|c|c|c|c|}
\hline$(P) \mathrm{F}$ & دو ماه بعد از & يك ماه بعد از & بلافاصله بعد از & قبل از مداخله & & & \\
\hline \multirow{2}{*}{$\cdot \mid \cdot \cdot 1<$} & $\Lambda V / T \cdot$. & VD/GT & $\Lambda \mu / \mu .$. & $\Lambda F / T$. & ميانگين & \multirow{2}{*}{ تروه كنترل } & \\
\hline & $1 \cdot / \pi F$. & $\mid r / F T \Lambda$ & V/TVA & אוF/N & انحرافمعيار & & \\
\hline \multirow{3}{*}{$\cdot 1 \cdot \cdot 1<$} & ১१/৭६४ & $\Delta r / G \ldots$ & $\Delta N / R_{T}$ & $V q / r 44$ & ميانگين & \multirow{3}{*}{\multicolumn{2}{|c|}{ اضاردارى }} \\
\hline & $9 / 9 .$. & Q/9Tr & g/TVG & $9 / \Gamma 40$ & انحرافمعيار & & \\
\hline & $\cdot|\cdot \cdot|<$ & $\cdot|\cdot \cdot|<$ & $\cdot|\cdot \cdot|<$ & $.1 \cdot 1 \Delta$ & $\mathrm{T}(P)$ & & \\
\hline
\end{tabular}

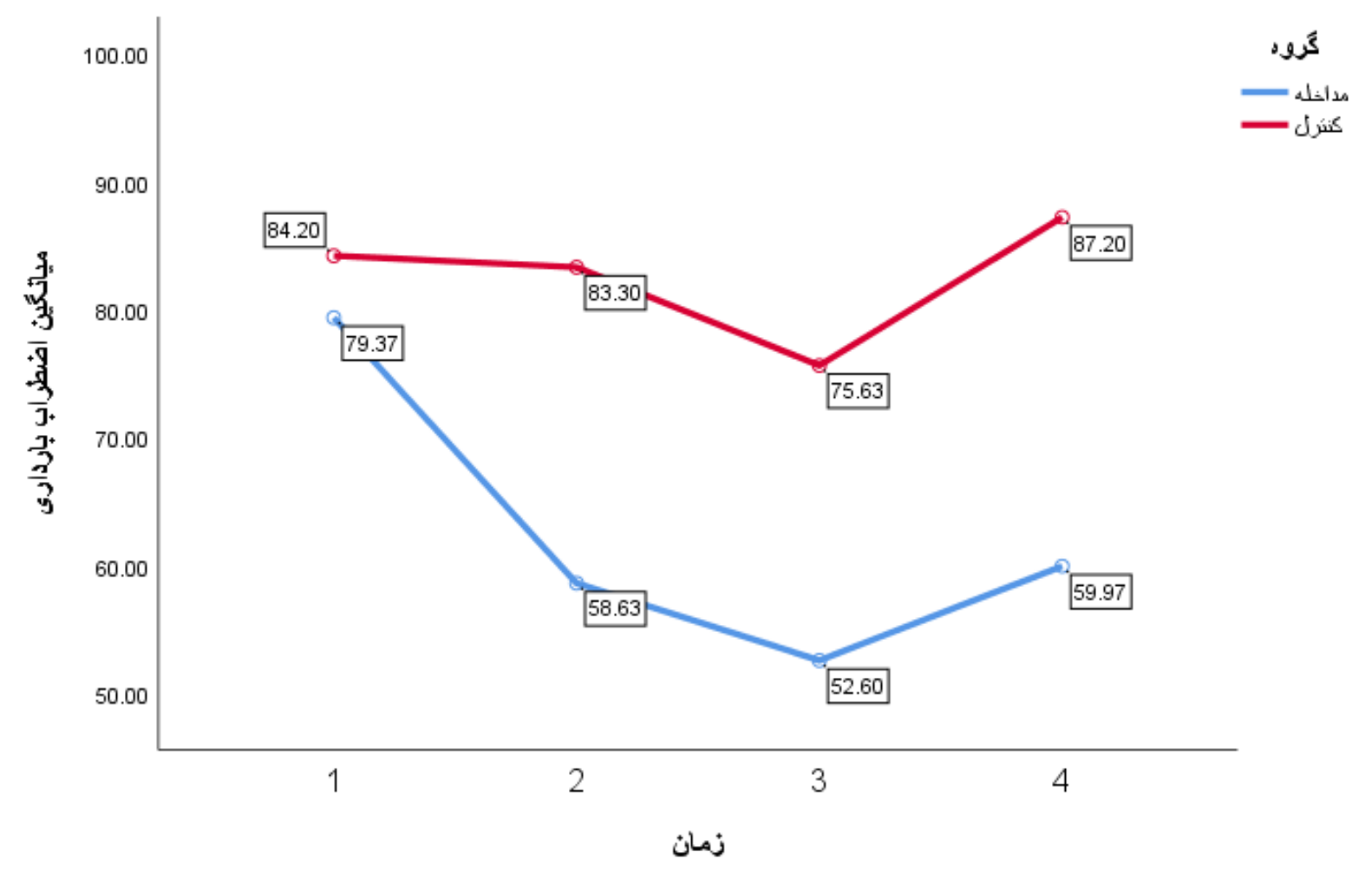

نمودار r. ميانگين اضطراب باردارى در تروههاى مداخله و كنترل قبل و بلافاصله، ا و ماه بعد از مداخله

بحث

در مطالعهاى كه توسط Karamouzian و همكاران در سال rوبا انجام شد نشان داد آموزش مديريت استرس به شيه شناختىرفتارى بر كاهش اضطراب و افسردكى دوران باردارى مؤثر بوده است كه مىتوان كفت كه با يزوهش حاضر همسو بود

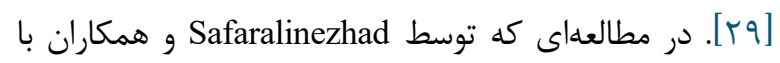
هدف بررسى تأثير مشاوره شناختىرفتارى گروهى بر افسردگى دونى

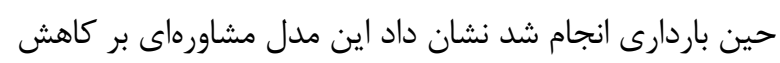

هدف از اين مطالعه بررسى تأثير مشاوره گروهى مبتنى بر

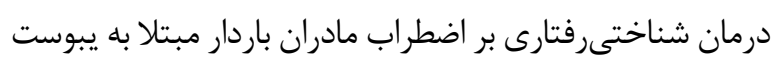

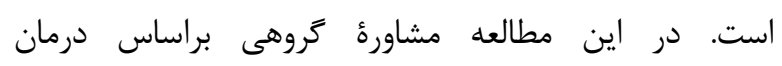
شناختىرفتارى توانست نمره كل اضطراب را در زروه مداخله

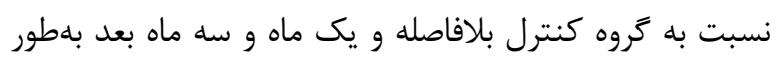

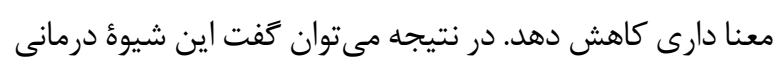
مؤثر بوده است. 
استفاده از درمان شناختىرفتارى بهعلاوه ملينها بهتر از

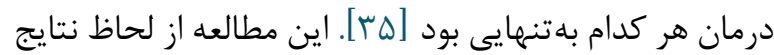

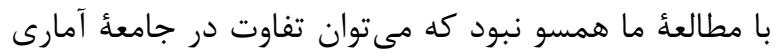
(اطفال) آن را از دلايل آن دانست.

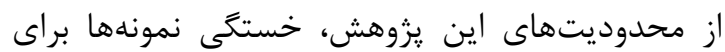
شركت در جلسات مشاوره بود كه باعث ريزش نمونهها مىشد. نيز بهدليل ماهيت مشاورهاىبودن مداخله، مطالعه

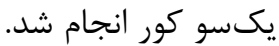

\section{نتيجه}

در اين يزوهش، مداخله مشاورهاى براساس درمان شناختىرفتارى بر اضطراب دوران باردارئ مدارى مؤثر بوده است.

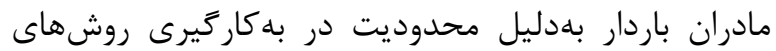

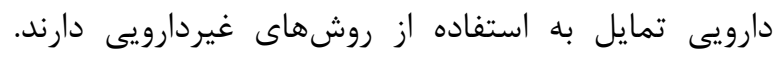

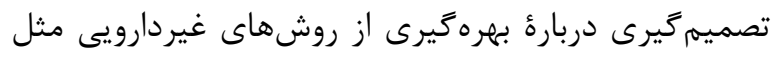

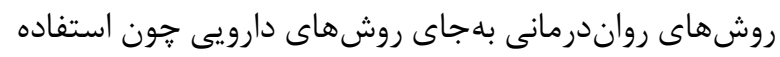
از ملينها كار دشوارى است. به هر حال تحقيقات بيشترى جهت تدوين يروتكلى براى راهنمايى زنان باردارى كه به به عوارض اضطراب مبتلا هستند، نياز است. مادران باردار و و بران مشاوران آنها در جريان تعامل با يكديكر براى تصميمَّيرى در اين خصوص بايد بتوانند بين مزايا و معايب استفاده از اين

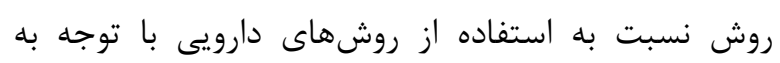

$$
\text { وضعيت باردارى به تعادل برسند. }
$$

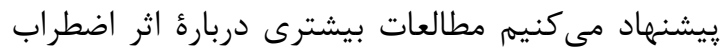

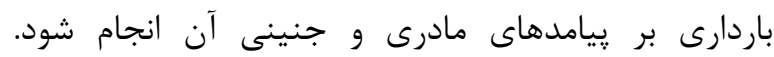

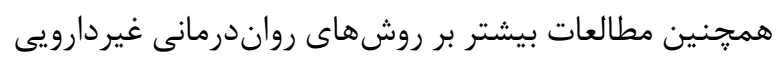

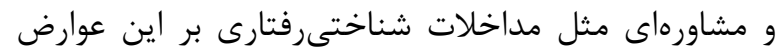

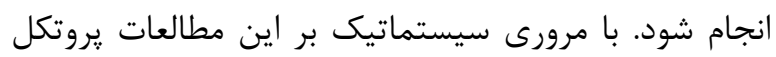

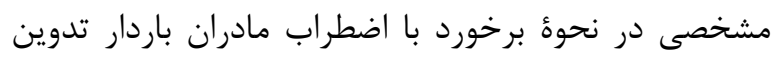

\section{سياسگزارى}

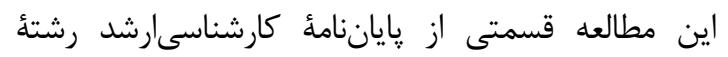

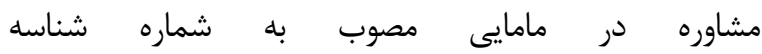
IR.QUMS.REC.1397.267 است. بدينوسيله از كاركنان شبكة دماره بهداشت و درمان شهرستان تاكستان كه در انجام اين يزوهش ما بار بنان را يارى نمودند، تشكر و قدردانى مىشود.
افسردگى در حين باردارى تأثير معنادارى داشته است [• [ـ].

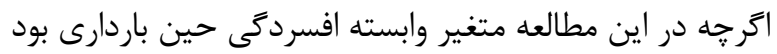

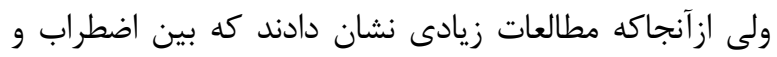

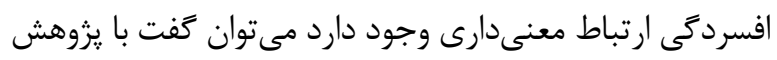
حاضر همسو بود [ابـ]

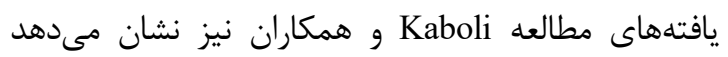
درمان شناختىرفتارى كروهى باعث كاهش اضطراب باردارى

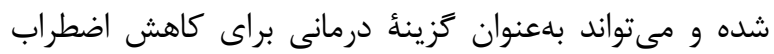

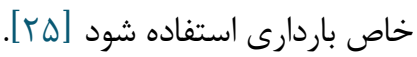
Lemon

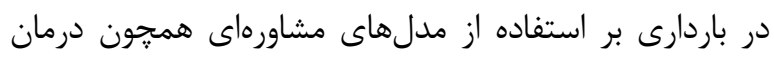

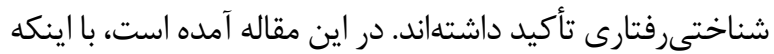

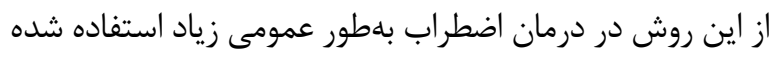

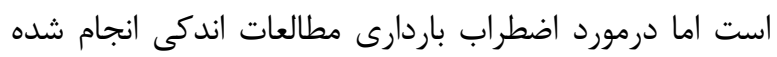

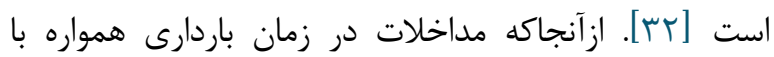

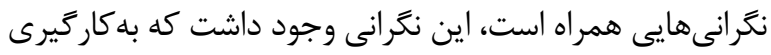

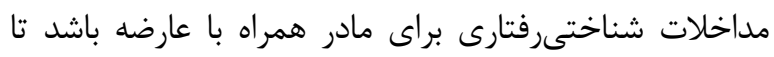

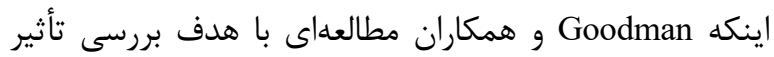
يكى از روشهاى رواندرمانى با نام ذهنآكاهى بر اضطراب آناب

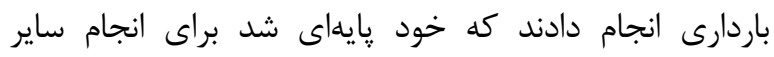

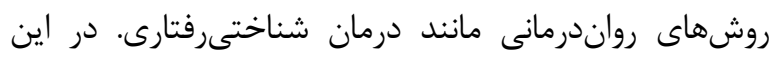

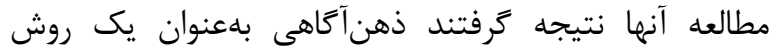

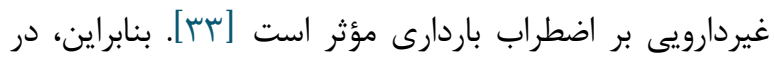

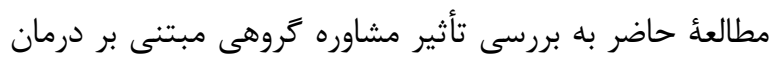

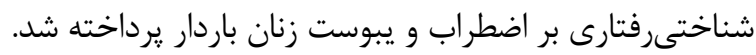
Arch

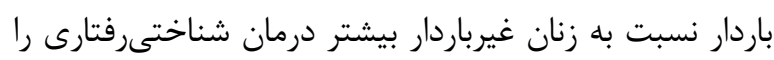
ترجيح مىدهند و وضعيت باردارى بر اين ترجيح مؤثر است. اين نين مىتواند بهعلت محدوديت استفاده از دارودرمانى براى درمان بران

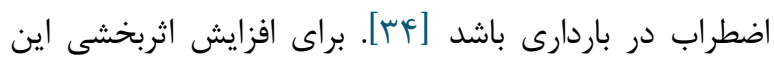

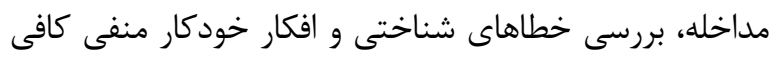

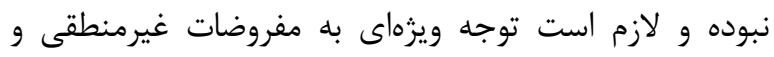

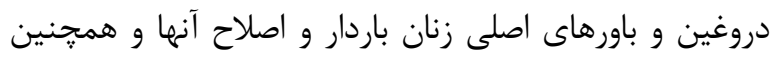

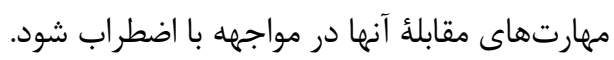
در مطالعهاى كه توسط Brazzelli و همكاران با هدف دمابل بررسى اثر درمان شناختىرفتارى بر يبوست اطفال انجام شد دان

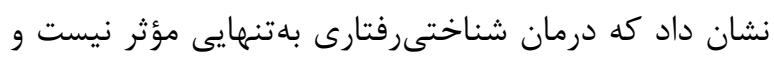

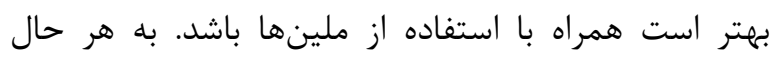


منابع مالى منابع مالى اين مطالعه توسط نويسندگان تامين شده است.

\section{References}

1. Cunningham, Gary F. williams obestrics. Translator? Tehran: Golban; 2018.

2. Dadsetan P. Developmental psychology from childhood to adulthood. Tehran: Organization of Reading and Editing Books. 2010.

3. Kane HS, Schetter CD, Glynn LM, Hobel CJ, Sandman CA. Pregnancy anxiety and prenatal cortisol trajectories. Biol Psych. 2014; 100:13-9. [DOI:10.1016/j.biopsycho.2014.04.003] [PMID] [PMCID]

4. Spielberger CD. Anxiety and behavior. Berlin: Academic Press; 2013.

5. Arch JJ. Pregnancy-specific anxiety: which women are highest and what are the alcohol-related risks? Compr Psychi. 2013; 54(3):217-28. [DOI:10.1016/j.comppsych.2012.07.010] [PMID]

6. Simon GE. Social and economic burden of mood disorders. Bio Psychi. 2003; 54(3):208-15. [DOI:10.1016/S0006-3223(03)00420-7]

7. Deklava L, Lubina K, Circenis K, Sudraba V, Millere I. Causes of anxiety during pregnancy. Procedia-Soc Behav Sci. 2015; 205:623-6. [DOI:10.1016/j.sbspro.2015.09.097]

8. Ertekin Pinar S, Duran Aksoy O, Daglar G, Yurtsal $\mathrm{ZB}$, Cesur B. Effect of stress management training on depression, stress and coping strategies in pregnant women: a randomised controlled trial. J Psychosom Obst Gynecol. 2017:1-8 [DOI:10.1080/0167482X.2017.1321632] [PMID]

9. Parsa P, Saeedzadeh N, Masoumi SZ, Roshanaei G. The effectiveness of counseling in reducing anxiety among nulliparous pregnant women. J Family Reproduc Health. 2016; 10(4):198.

10. Kammerer M, Adams D, Von Castelberg B, Glover V. Pregnant women become insensitive to cold stress. BMC Preg Childbirth. 2002; 2(1):8. [DOI:10.1186/1471-2393-2-8] [PMID] [PMCID]

11. Al'Absi M, Petersen KL, Wittmers LE. Adrenocortical and hemodynamic predictors of pain perception in men and women. Pain. 2002; 96(12):197-204. [DOI:10.1016/S0304-3959(01)00447-X]

12. Allolio B, Hoffmann J, Linton E, Winkelmann W, Kusche M, Schulte HM. Diurnal salivary cortisol patterns during pregnancy and after delivery: relationship to plasma corticotrophin-releasinghormone. Clin Endocrinol. 1990; 33(2):279-89. [DOI:10.1111/j.1365-2265.1990.tb00492.x] [PMID]

\author{
تعارض در منافع \\ بين نويسندًان هيجَّونه تعارضى در منافع وجود ندارد
}

13. Lenz HJ, Raedler A, Greten H, Vale WW, Rivier JE. Stress-induced gastrointestinal secretory and motor responses in rats are mediated by endogenous corticotropin-releasing factor. Gastroenterol. 1988; 95(6):1510-7. [DOI:10.1016/S0016-5085(88)800702]

14. Mazaheri M, Manshaee GR. Comparing the cognitive-behavioral aspects of pain and pain acceptance based on mindfulness level in patients with functional gastrointestinal disorders. Feyz J Kashan Uni Med Sci. 2016; 20(1):64-72.

15. Casper D. Harrison 's principles of internal medicine. Harvard: Harvard Medical School; 2015.

16. Derbyshire E, Davies J, Costarelli V, Dettmar P. Diet, physical inactivity and the prevalence of constipation throughout and after pregnancy. Matern Child Nutr. 2006; 2(3):127-34. [DOI:10.1111/j.17408709.2006.00061.x] [PMID] [PMCID]

17. Cullen G, O'Donoghue D. Constipation and pregnancy. Best Pract Res Clin Gastroenterol. 2007; 21(5):807-18. [DOI:10.1016/j.bpg.2007.05.005] [PMID]

18. Tadataka Y. Textbook of Gastroenterology. Washington D.C.: Wiley Blackwell; 2016.

19. Hinkle JL. Brunner \& Suddarth Textbook for medical surgical nursing. Philadelphia: Lippincott Williams \& Wilkins; 2014. p. 136.

20. Ghaffari F, Poor Ghaznain T, Shamsalinia A. Effect of sole reflex on pregnant women's constipation severity. Iran J Obstetric Gynecol Infertil. 2007; 10(2):27-38.

21. Trottier M, Erebara A, Bozzo P. Treating constipation during pregnancy. Canad Family Phys. 2012; 58(8):836-8.

22. Alipour M, Ghahremani L, Amooee S, Keshavarzi S. The effectiveness of relaxation techniques on depression, anxiety and stress in pregnant women: based on self-efficacy theory. Sci J Kurdistan Uni Med Sci. 2017; 22(3):20-30.

23. Kianifar H, Kiani M, Hosseini S, Jafari S, Ahanchian H, Khakshour A. Comparison of Life Quality and Psychiatric comorbidity in Healthy Children and Teens and the Ones with Constipation. J North Khorasan Uni Med Sci. 2016; 8(1):125-34. [DOI:10.29252/jnkums.8.1.125]

24. Larina K, Roh LD. Concise guides to mental health anxietydisorders. Tehran: Arjmand; 2016. 
25. Kaboli KS, Mahmoodi Z, Tourzani ZM, Tehranizadeh M, Kabir K, Dolatian M. The effect of group counseling based on cognitive-behavioral approach on pregnancy-specific stress and anxiety. Shiraz Med J. 2017; 18(5):e13183. [DOI:10.5812/semj.45231]

26. Karamoozian M, Askarizadeh G, Behroozi N. The study of psychometric properties of pregnancy related anxiety questionnaire. J Clin Nurs Midwifery. 2017; $5(4): 22-34$.

27. Esfandiari M, Faramarzi M, Amiri FN, Parsian H, Chehrazi M, Pasha H, Omidvar S, GHolinia H. Effect of supportive counseling on pregnancy-specific stress, general stress, and prenatal health behaviors: A multicenter randomized controlled trial. Patient Education and Counseling. 2020 May 5. [DOI:10.1016/j.pec.2020.04.024] [PMID]

28. Jesse Wright B. learning Cognitive-Behavior Therapy. Translator ?. Tehran: Arjmand; 2017.

29. Karamoozian M, GhA. Effectiveness of cognitivebehavioral stress management intervention on anxiety and depression during pregnancy. J Kerman Uni Med Sci. 2014; 20(6):606-21

30. Safaralinezhad A, Oveisi S, Jourabchi Z. Effect of cognitive-behavioral group therapy on gestational depression: A clinical trial. Iran J Obst Gynecol Infertil. 2018; 21(2):48-59.

31. Nazemian F, Ghafari F, Poorghaznein T. Evaluation of depression and anxiety in hemodialysis patients. medical J Mashhad Uni Med Sci. 2008; 51(3):171-6.

32. Lemon EL, Vanderkruik R, Dimidjian S. Treatment of anxiety during pregnancy: room to grow. Arch Women Ment Health. 2015; 18(3):569-70. [DOI:10.1007/s00737-015-0514-3] [PMID]

33. Goodman JH, Guarino A, Chenausky K, Klein L, Prager J, Petersen R, et al. CALM Pregnancy: results of a pilot study of mindfulness-based cognitive therapy for perinatal anxiety. Arch Women Ment Health. 2014; 17(5):373-87. [DOI:10.1007/s00737013-0402-7] [PMID] [PMCID]

34. Arch JJ. Cognitive behavioral therapy and pharmacotherapy for anxiety: treatment preferences and credibility among pregnant and non-pregnant women. Behav Res Ther. 2014; 52:53-60. [DOI:10.1016/i.brat.2013.11.003] [PMID]

35. Brazzelli M, Griffiths P. Behavioural and cognitive interventions with or without other treatments for defaecation disorders in children. The Cochrane database of systematic reviews. 2001; (4):CD002240CD. [DOI:10.1002/14651858.CD002240] 